\title{
CRÍTICA DE LAS CIUDADES DARWINISTAS: EL PENSAMIENTO ANARQUISTA
}

\section{CRITICISM OF THE DARWINIAN CITIES: ANARCHIST THOUGHT}

Ricardo Melgar Bao

\section{Resumen}

A lo largo de este ensayo pasaremos apretada revista a las ciudades darwinistas de la segunda mitad del siglo XIX hasta 1914, víspera de la Primera Guerra Mundial. A continuación, mencionaremos algunos procesos de desarrollo urbano y sus problemáticas, a través de las reflexiones y narrativas utópicas de los intelectuales libertarios. Continuamos con el análisis de la obra de Manuel González acerca de la cuestión urbana y el drama de la ciudad de Lima.

Palabras clave: ciudad darwinista; anarquismo; ciudad de Lima; Manuel González Prada.

\section{Abstract}

Throughout this essay we will make a tightly review the Darwinian cities of the second half of the nineteenth century until 1914, the eve of World War I. Next, we will mention some processes of urban development and its problems, through the utopian reflections and narratives of the libertarian intellectuals. We continue with the analysis of the work of Manuel González on the urban issue and the drama of the city of Lima.

Key words: Darwinian city; anarchism; city of Lima; Manuel González Prada. 
El progreso y las ciudades darwinistas

E1 proceso de urbanización ascendente del siglo XIX fue impactante, más para los países europeos y Estados Unidos, que para los ubicados en los continentes periféricos y subalternos. Representó el signo visible de la modernización capitalista. Las ciudades en desarrollo tuvieron algunos vínculos entre sí, mediadas por los viajeros, la circulación de ideas y de bienes manufacturados, industriales y artísticos. En cierto sentido, las ciudades metrópolis desempeñaron el papel de espejo o paradigma para las otras, pareciendo concentrar los valores del progreso y del desarrollo cultural más allá de la reproducción ampliada de la desigualdad social, la explotación de la fuerza de trabajo, el control social autoritario y la alienación. Sin embargo, fueron estas aristas no deseables de la urbanización las que suscitaron críticas de mayor o menor calibre, acciones de protesta, y temáticas literarias y artísticas.

La expansión demográfica de varias ciudades implicaba flujos migratorios internos e internacionales y tasas altas de natalidad, a pesar de las bajas generadas por las pestes, epidemias y condiciones de vida precarias de las clases subalternas. Al iniciarse el siglo XIX, no había en todo el sistema occidental una ciudad que alcanzase el millón de habitantes. A mediados de siglo, Londres tenía 2 millones, y París más de un millón. Fuera de ellas, al concluir el siglo, varias ciudades pasaban del millón de pobladores. En Europa: Berlin, Moscú, San Petersburgo y Viena; en Estados Unidos: Chicago, Filadelfia y Nueva York; en Asia: Tokio y Calcuta. (Munford, 2012: 885). Una mirada histórica señala con propiedad que el siglo XIX se caracterizó por la confluencia de las fuerzas de la civilización industrial en Europa y Estados Unidos. La concentración del capital y de la industria, fue acompañada del crecimiento poblacional para atender las oscilantes necesidades de fuerza de trabajo, incluida una base de reserva. La segunda mitad del XIX fue de la constitución de carteles, trust, monopolios, sociedades por acciones, que dotó de nueva forma al poder económico. A mediados de siglo, la mitad de la población en Inglaterra y Bélgica vivía en ciudades y, a fin de siglo, tres cuartas partes. En Alemania, en 1871, había 8 ciudades de cien mil habitantes o más, en 1900 pasaron a 33 y en 1910 a 48. En Estados Unidos, en 1900, sus diez ciudades más grandes concentraban la octava parte de su población. (Bruun, 1964, pp. 158-159).

Por su lado, las ciudades latinoamericanas comenzaron gradualmente a recibir el impacto modernizador del nuevo orden económico mundial, logrando su nueva fisonomía al fin del periodo (1880). El crecimiento urbano y portuario se explicó, en lo fundamental, por las necesidades económicas y sociopolíticas de la economía de exportación, las cuales se tradujeron en una red de servicios comerciales, bancarios, bursátiles y de seguros; de 
servicios de infraestructura (telégrafos, transporte ferroviario y muelles de embarque), así como del establecimiento de centros nacionales de decisión, control y legitimidad política.

Los viejos rostros de las ciudades coloniales fueron afectados en sus límites: arquitectura y servicios urbanos (drenaje, iluminación a gas, ampliación y empedrado de calles, transporte urbano colectivo). Demográficamente, estas ciudades comenzaron su fase de crecimiento cosmopolita. El peso de la inmigración europea y rural alteró el modo de vida urbano, la cultura y la política. Así tenemos que Río, que en 1819 tenía 113.000 habitantes, pasó a tener 267.000 en 1872; Buenos Aires, de 38.000 habitantes en 1800, alcanzó en 1869 una población de 178.000; Lima, de 64.00 pobladores en 1812, pasó la barrera de los 100.000 en 1876; la ciudad de México, hacia 1877 totalizó una población de 230.000 habitantes. Otras capitales, como Caracas y Bogotá, se mantuvieron demográficamente estables y por debajo de los 50.000 habitantes. Pero, en general, las ciudades aparecieron como "las vanguardias de civilización y el progreso" (Carmagnani, 1984, p. 53).

Otras ciudades, portuarias, aparecieron también en primer plano: Bahía Blanca y Rosario en Argentina; Valparaíso en Chile; Mollendo en Perú; Tampico en México; Colón en Panamá; y Barranquilla en Colombia. Habria que sumar a estas las emergentes ciudades mineras de Chile, Bolivia y México. El desarrollo de la industria de la construcción, el transporte colectivo y las empresas gráficas, apuntalaron la conformación de los primeros contingentes del proletariado moderno en las ciudades y puertos latinoamericanos, dándole una nueva fisonomía a los alineamientos clasistas emergentes. De otro lado, la burguesía nativa, de representar únicamente al capital comercial, se asumió, no sin ciertas contradicciones, como capital bancario e industrial. La industria de la construcción, favorecida por la iniciativa modernizante del Estado liberal-oligárquico, emprendió la edificación sostenida de importantes obras públicas (edificios, parques, carreteras, puentes, vías férreas, muelles, drenaje, alumbrado, teatros, hospitales, etc.). La demanda masiva de albañiles, picapedreros, carpinteros, yeseros, herreros, marmolistas, quebró la estructura gremial, impulsando la proletarización y democratización de los oficios. Las ciudades se fueron transformando en América Latina. E1 parteaguas se dio a mediados del siglo XIX. Comparto la siguiente caracterización de dicho proceso:

...si las ciudades del proyecto liberal latinoamericano de 1850 habían sido consideradas como "Atenas" posibles e idealizadas, a lo largo de medio siglo de realización de sus programas, se trocaron en "Sodomas" degradadas en términos morales y edilicios, o en "Babilonias" multitudinarias y agresivas.

[...] Pero quienes más padecían los resultados de ese darwinis- 
mo social eran los habitantes de los suburbios miserables, antítesis y correlatos de los "celestiales barrios del centro" [...]. Eran los de abajo: hombres y mujeres de "las penumbras, los sótanos, el encogimiento y la pestilencia" que ya habian tenido como voceros a los anarquistas (Viñas, 1983, p. 16).

Destacaremos, en este proceso de urbanización, el papel del artesanado en la vida económica, social, cultural y política de la segunda mitad del siglo. Este heterogéneo sector social urbano fue el principal mediador en la redefinición de la politicidad de las ciudades y de su hinterland rural. Supo incorporar al quehacer político citadino a las masas, a través de un nuevo clientelismo al servicio de las élites de filiación liberal o conservadora, vía las sociedades mutuales, pero también a través de proyectos de autonomía popular de signo nacionalista antioligárquico.

El primer mutualismo artesanal fue estimulado profundamente por el ciclo de epidemias (cólera o morbo asiático, influenza, fiebre amarilla, etcétera), el cual acompañó al desarrollo del nuevo orden latinoamericano, afectando principalmente puertos y ciudades. Esta oleada de epidemias fue un epifenómeno de la ampliación del mercado mundial, de la revolución tecnológica de las vías y medios de transporte, así como del empeoramiento de las condiciones sanitarias en los barrios pobres de las de las ciudades en proceso de modernización. El cólera o morbo asiático tuvo como núcleo endémico a Bengala, propagándose por la India y el Asia meridional, hasta alcanzar las costas europeas y Egipto. De Europa llegó el cólera a las costas americanas cuatro o cinco años después de haber estallado el brote epidémico en Asia. La fiebre amarilla tuvo como centro endémico a las costas tropicales del Caribe, propagóse de ahí hacia Sudamérica, y llegó hasta Europa, vía el tráfico con España. Estos flagelos fueron verdaderos azotes de las ciudades latinoamericanas en la segunda mitad del siglo XIX (Sánchez Albornoz, 1977, pp. 187-188).

Las epidemias de cólera en Cuba (1855), y fiebre amarilla en Río (1856), Montevideo (1857), Buenos Aires (1871), Valparaíso y Santiago (1873), dejaron saldos de alta mortalidad urbano-portuaria. Si bien la epidemia atacaba a los diferentes estratos sociales, se encarnecía sobre los sectores que vivian en mayor hacinamiento y peores condiciones de salubridad. Las epidemias propiciaron diferentes estrategias sociales para paliar los letales y nocivos efectos.

Se puede encontrar una cierta correlación entre el desarrollo de las sociedades mutuales de algunas ciudades y puertos, con los brotes de epidemias que le antecedieron. La prensa obrera y artesanal fue muy sensible al cubrir notas sobre la secuela social de las epidemias. La fe en los nuevos descubrimientos de la medicina moderna fue acompañada de mayores expectativas en las sociedades mutuales, así como de un cierto reclamo a los go- 
biernos de turno por el abandono de las clases menesterosas. No obstante, las mutuales fracasarian en su intento de paliar las carencias de los deudos. La función preventiva de las mutuales, frente a experiencias de brotes epidémicos, fue desconsoladora.

Las epidemias estimularon también la sátira y la crítica social frente a los gobiernos y patronos. A raíz de un brote de fiebre amarilla en Lima y Callao, el presidente del Perú, Ramón Castilla, se refugió con el gobierno en pleno en el aislado y aristocrático balneario de Chorrillos. Una letrilla que se hizo muy popular, decía cáusticamente: "A Chorrillos fue Ramón / lleva naipes, lleva dados, / lleva música y soldados, / también lleva Convención. /Porque le asusta se va / aquella fiebre amarilla / y huye también la gavilla / que al Perú leyes da/. ¿Habrase visto un accidente como éste? / Tener miedo una peste de otra peste». De otro lado, se fue modelando una corriente de intelectuales críticos, adscritos a mediados del siglo XIX al socialismo romántico, como Enrique Alvarado, José Casimiro Ulloa, los hermanos Francisco y Manuel Bilbao, los cuales vivían su estación de exilio en la ciudad de Lima. La relación de estos intelectuales con los artesanos y tipógrafos permitió otra manera de encarar las urgencias de Lima y de la nación.

Joaquín Capelo, en su libro Sociología de Lima, estimaba que, de la población capitalina del último cuarto del siglo XIX (calculada en 100,000 habitantes), un $16 \%$ se desempeñaba en los siguientes rubros artesanales: albañiles, sombrereros, zapateros, sastres, carpinteros, entre otros. Las categorias de maestros, oficiales y operarios ayudantes, habian perdido los privilegios que proporcionaban las ya osificadas estructuras corporativas de los gremios artesanales propias de la Colonia y de la primera mitad del siglo XIX; tal es así que los operarios se habían convertido en una categoría eventual de trabajadores a domicilio, y los oficiales, de manera gradual y generalizada, en semiproletarios, y, en el mejor de los casos, se habían incorporado a las filas del naciente proletariado fabril.

\section{Progreso y visión urbanocéntrica}

Apreciar el desarrollo de la ciudad en términos históricos tuvo expresiones diversas. Denominamos ciudades darwinistas a las que, a partir de la segunda mitad del siglo XIX, asociaron la idea de progreso al bienestar, a la concentración del poder económico y político de las élites,s y al control y represión de los de abajo, obreros y parias. La visión de las élites autoritarias justificaba y naturalizaba a la ciudad como pivote y hechura del progreso y, por ende, de la civilización occidental. Otros, desde una perspectiva más amplia, se interrogaban sobre el desarrollo, crisis y ruinas de las ciudades antiguas. Hubo también posturas, como la de Piotr Kropotkin, que veían en la gran ciudad de su tiempo un palimpsesto, develando sus sumergidas o borradas fisonomías arquitectónicas ${ }^{1}$. 
William Morris, el socialista libertario inglés, miraba en las pequeñas ciudades, el espejo del camino seguido por las grandes ciudades antiguas ${ }^{2}$.

La crítica de la ciudad durante el arco temporal explorado, entre finales del siglo XIX y 1914, no fue ajena a la mirada histórica, ni a la toma de distancia frente a su contradictorio presente, maquillado por la ideología de progreso. Abrevó en las siguientes fuentes: el romanticismo, por su desconfianza en la ciencia y tecnología aplicada a su espacio de vida; la enfermedad y mortandad, generadas por la difusión de pestes o las condiciones precarias de vivienda, alimentación deficitaria y sanidad en los barrios obreros y populares; y, por último, la publicación y difusión de los proyectos y utopías urbanas de filiación anarquista o socialista, algunos vinculados a los proyectos migratorios comunitarios. De otro lado, apareció un contradictorio discurso y representación acerca de la naturaleza y la vida rural. Sumándose a todo ello, incidió la oleada armamentística de finales del siglo XIX, la cual sacudía a las más importantes ciudades y países europeos. Las fricciones y disputas anglo rusas por el dominio del Asia persistían, a pesar del acuerdo de 1887. No fue menor el clima de tensión entre la monarquía austro-húngara y Rusia por los Balcanes, y la disputa por la dominación del continente africano.

La publicación de algunas obras narrativas, de parecido corte, retrataron el desencanto de un sector intelectual y popular frente a los lastres de las principales ciudades industriales. La ciudad dejaba así de ser celebrada, dados los problemas generados por el desarrollo capitalista que se desprendió de la segunda revolución industrial. Este desencanto y crítica se puede leer en las siguientes obras acerca de las ciudades vitrina, como Londres, Nueva York y París: La ruina de Londres (1892), de Robert Barr; El ciudadano 504 (1896), de Charles E. Palmer; La isla que se volcó (1909), de Thomas J. Vivian y Grenna J. Bennet (Giacchino, 1978). En la narrativa naturalista y republicana de Emilio Zola, París, Londres, Roma, muestran sus contradicciones y su lado oscuro, el de la pobreza. Sin embargo, fue más allá de narrar el drama contemporáneo de algunas de las principales ciudades europeas. Elaboró una utopía urbana en su novela Trabajo (1901), para lo cual resimbolizó el pesebre de la tradición cristiana, para dotarlo de una función laica y de orientación socialista en proceso de confrontación con un espacio industrial capitalista, en la que estaban engazados los obreros y sus viviendas a la fábrica y fundición acerera, llamada, con especial ironía, el Abismo. Tan simbólico nombre le permitió a Zola procesar la polaridad que la enfrentaba a la Crècherie, preanunciando que su fase de bonanza sería temporal, y que la crisis y el incendio la llevarian a la ruina. Explícitamente afirmó que dicha confrontación representaba a las fuerzas antagónicas del capitalismo y del socialismo. La lógica de la lucha se inscribió en un horizonte evolucionista, aunque men- 
cionó escenarios y procesos de mediación. Momento culminante de la novela gira en torno a la reconstrucción del Abismo, con la ayuda y asesoría de los obreros de la Crècherie. La crítica a la ciudad está enlazada a una posición antiarmamentista y antiguerrerista.

En su formación ideológica tardía, se ha subrayado la presencia del legado fourierista. La fundición dejó en la memoria obrera su historia negra y deprimente, donde "el salario había respirado agonizante" (Zola, 1991, p. 430). Otro París era posible, considerando el hecho de que:

El ejemplo de la Crècherie se hacía contagioso. No eran teorías, eran hechos; se iban ganando hombres y terrenos del contorno; nuevos obreros brotaban doquiera. En tres años dobló la población de la Crècherie; la progresión se aceleraba. Era la ciudad soñada, la ciudad del trabajo reorganizado, otra vez noble; la ciudad futra de la dicha conquistada, camino de ser metrópoli. Los talleres, todas las construcciones, crecian, cubrian hectáreas; y las casitas claras y alegres entre verdes jardines se multiplicaban (Zola, 1991, p. 406).

Una visión urbanocéntrica poblaba el imaginario de muchos anarquistas entre fines del siglo XIX y principios del siglo XX, reconciliando la modernización, la nueva moral, la igualdad, la justicia y la libertad. Esta utopía urbana contrastó con una vertiente narrativa occidental que ficcionali- zaba sobre la ruina del tejido social o material de las grandes ciudades, como Londres. Morris dio forma a una utopía urbana en su ensayo News from Nowhere (1890), y Eliseo Reclus le dio figura lírica a la suya en La Ciudad del Buen Acuerdo (1895) ${ }^{3}$. El mismo año, Reclus, hablando de la ciudad real y viable, ratificó, en la segunda, su condición de pivote de la civilización y del progreso:

... es fácil demostrar que este crecimiento monstruoso de la ciudad, complejo resultado de una multiplicidad de causas, no es pura patologia: por un lado, en algunos de sus aspectos, constituye para el moralista un fenómeno espantoso, por otro, cuando se desarrolla normalmente, es el signo de una evolución sana y regular. Allí donde crecen las ciudades, la humanidad progresa; allí donde decaen, la propia civilización está en peligro ${ }^{4}$.

Por su lado, Kropotkin, en La conquista del pan (1892), al reflexionar acerca de la Europa burguesa, urbanizada e industrializada, en las que el proletariado mal vive, no olvidó referir sus preocupaciones en torno a la amenaza que representaba la industria armamentista, por sus implicaciones guerreristas:

Basta citar los miles de millones gastados por Europa en armamento, sin más fin que conquistar mercados, para imponer la ley económica a los vecinos $\mathrm{y}$ 
facilitar su explotación; los millones pagados cada año a funcionarios de todo tipo, cuya misión es mantener el derecho de las minorias a gobernar la vida económica de la nación; los millones gastados en jueces, cárceles, policías y todo ese embrollo que llaman justicia, cuando alcanza, como es sabido, con aligerar tan sólo un poco la miseria de las grandes ciudades para que la criminalidad disminuya en proporciones considerables... (Kropotkin, 2005, p. 33).

Kropotkin configuró la ciudad futura, ideal, a partir de la fuerza de la necesidad alimentaria del pueblo trabajador y de su tradición de ayuda mutua. París, al igual que otras ciudades burguesas, genera opulencia para sus élites, y miseria para los obreros y parias. La toma del poder en manos del pueblo y su consecuente cambio en el modo de vida, idealiza la afirmación y viabilidad de una zona liminar, es decir, semi urbana:

Por la fuerza de las cosas, el pueblo de las grandes ciudades se verá obligado a apoderarse de todos los viveres, procediendo de lo simple a lo complejo, para satisfacer las necesidades de todos los habitantes.[...] Es principalmente alrededor de las grandes ciudades -de París sobre todo-donde se agrupan los parques y jardines de los señores, millones de hectáreas que no esperan más que el trabajo inteligente del cultivador, para rodear, por ejemplo, a París de llanuras mucho más fértiles y productivas que las estepas cubiertas de humus, pero desecadas por el sol, del sur de Rusia (Kropotkin, 2005, pp. 72 y 83).

Jean Grave, amigo de Kropotkin, fue más allá de la visión crítica de éste, así como de las enunciadas por Morris y Reclus acerca de la ciudad ${ }^{5}$. En su ensayo La Ciudad Futura (1895), resignificó la tesis social darwinista sobre la sobrevivencia del más fuerte, en la que se apoyaban las clases dominantes para oprimir y expoliar al proletariado y a los pueblos colonizados, sin escapar a su matriz interpretativa. Grave idealizó la fuerza y el destino teleológico del proletariado al escribir, con ánimo subversivo y tono de proclama:

Abajo los prejuicios estúpidos, abajo el respeto idiota a las instituciones seculares, abajo la falsa moral; nosotros somos los más fuertes, los mejor dotados, puesto que después de una serie innumerable de siglos luchamos contra el hambre y la miseria bajo un trabajo abrumador, en condiciones mortales de higiene, de insalubridad manifiesta, y estamos todavía vivos; somos los más aptos, puesto que nuestra producción y nuestra actividad son las que permiten mantenerse a vuestra sociedad ${ }^{6}$.

William Morris, al darle forma narrativa a su utopía urbana, pensaba en reconvertir a Londres en un espacio 
en el que la máquina y la tecnología no generan ni desigualdad ni subalternidad. En su Londres imaginado florecen conjuntos diseminados de aldeas con jardines, en donde el trabajo dignifica y alegra la vida en común. Las familias eran relevadas por uniones libres de pareja.

Cierra este arco temporal desde Buenos Aires, La ciudad anarquista americana (1914) de Pierre Quiroule, el cual realizó una autopsia clasista de la ciudad burguesa, la real, antes de proponer su utopía:

Sabido es que la burguesía se compone de individuos que viven del trabajo ajeno. Estos individuos, que son los parásitos que roen el cuerpo social, no podrian existir o desarrollarse fuera del recinto de las ciudades. Es preciso, pues, que haya ciudades para albergarlos convenientemente, y que estas ciudades sean grandes, porque cuanto más grandes, más numerosos son los servicios públicos que ellas necesitan, los cuales exigen todo un arsenal de ordenanzas y reglamentos que faciliten su buen funcionamiento. Estos reglamentos y ordenanzas requieren, como es de suponer, una legión de "activos" funcionarios que velen por su exacto cumplimiento (Quiroule, 1914, s/p).

Frente a esta realidad que le resulta opresiva y ajena a las clases subalternas, justifica como vía de resolu- ción, las acciones revolucionarias de las masas:

Sí, todo es ilusión en las grandes ciudades, todo, hasta la salud, que no tenemos; hasta el aire que respiramos, viciado por las miasmas y pestilencias de la calzada: ¿no hemos dicho que el barrido de la vía pública es otra ilusión?

[...] contra ellos, cientos de puños se levantan traduciendo en gesto de rabia impotente la desesperación de los desgraciados seres que viven en su base privados de luz, de aire y de sol, en las miserables chozas envueltas en la fría sombra que proyecta sobre ellas el criminal coloso, sembrador de tristeza, de tuberculosis y de muerte... (Quiroule, 1914, s/p).

La utopía de Quiroule al asumir la defensa de una red de comunas rurales que no era contraria a los beneficios de la tecnología, el higienismo y las ciencias de la salud y la reinvención de los ocios, llevó a su clímax la crítica de la ciudad darwinista. Para nuestro pensador libertario la gran ciudad no era deseable ni viable por lo que proponía su negación a través de las comunas rurales de nuevo tipo. El trabajo digno y la salud colectiva de los habitantes no eran posibles en las ciudades grandes, por la inhumana explotación existente de la fuerza de trabajo, la contaminación, la insalubridad y por tener, seguramente presente, la mortandad causada por las 
recurrentes epidemias internacionales:

...proclamar la libertad sin límite y el derecho a la salud en la región americana emancipada, organizando el trabajo sobre bases nuevas que no aten al individuo a un modo determinado de labor y de vida. Y, sobre todo, huir de las grandes ciudades, derribarlas implacablemente hasta que no quede de ellas piedra sobre piedra, como si fueran ciudades malditas..., y formar pequeños pueblos que produciéndolo todo, se basten a sí mismos. Respirar aire puro, vivir en plena gloria del sol, para dar nuevos pulmones a la humanidad y regenerar la especie, reconciliándola con la alegría y la dicha de ser [...] con el trabajo libre e inteligente de sus habitantes, las comunas nacientes llegarian en poco tiempo a un alto grado de progreso benéfico para todos sus miembros, acercándose cada vez más al ideal de perfección soñado por los generosos utopistas (Ibíd.).

\section{González Prada: critica de la ciudad, la civilización y el colonialismo}

La valoración de la evolución de la humanidad tiene un lugar cultural por excelencia: la ciudad. La visión de González Prada de la ciudad tuvo deudas con el positivismo, pero también con el romanticismo de Víctor Hugo, y con el pensamiento anarquista, parti- cularmente de Eliseo Reclus y de Piotr Kropotkin.

Exploremos la manera en que González Prada enfocó y valoró, desde referentes higienistas modernos, a las ciudades peruanas, frente a sus pares del continente y a las europeas. Con respecto a las primeras escribió: "Ninguna de nuestras ciudades rivaliza con Buenos Aires, Montevideo ni Santiago: en todas ellas se palpa la estagnación o la ruina, sobre todas pesa una atmósfera de hospital y cementerio" (González P., 1933, p. 162). La ciudad de Lima resentía todavía los efectos del saqueo y la ocupación militar chilena, tras la derrota peruana en la denominada Guerra del Pacífico (1879-1882), a los que se sumaron las acciones depredadoras de la guerra civil de 1895.

Nombrar a la serie hospital y cementerio sugería hablar de ciudad enferma, de ciudad cadáver, en tiempos en que las fantasmagorias de la peste estaban muy presentes en el imaginario social. Consideró nuestro pensador que la peste del clero católico y las pestes del cuerpo eran dos calamidades sociales que debían ser atendidas con medidas profilácticas científicas, educativas, médicas e higienistas. De las segundas, González Prada no pudo dejar de evocar al "médico que lucha brazo a brazo con la muerte en la ciudad asolada por la peste" (1894, p. 37); en otro pasaje de Pájinas Libres, mencionó el azote demográfico de la fiebre amarilla (p. 30). A través de la problemática urbana, nuestro autor configuró simbólicamente una modernización 
negada, una modernidad ausente.

Manuel González Prada asumió, así, una perspectiva modernizante y occidental, frente a la cuestión urbana y su progreso. De este modo ubicó, entre las ciudades más desarrolladas, a París, Roma, Viena, Berlín, San Petersburgo y Nueva York. Pensando en la potencialidad de ellas, construyó una utopía urbana, capaz de reproducirse, configurando "hermosas ciudades higiénicas" y hedonistas (la enuncia como la "dulzura del vivir"), sólo reconciliables bajo su ideal anárquico. Si la "urbanización de la tierra", afirmaba nuestro intelectual libertario, ha sido un legado histórico del trabajo de la humanidad, logrado en el transcurso de siglos, le resultaba ilegítima su apropiación privada en manos de los multimillonarios (Morgan, Carnegie, Rockefeller, Rothschild) y de todos los ricos del mundo. La alternativa sólo era una: si la "Humanidad de ayer produjo $y$ capitalizó; a la Humanidad de hoy toca recibir la herencia: lo de todos pertenece a todos" (González P., 1948, p. 23).

Inaugurado el siglo $\mathrm{XX}$, la retórica médica e higienista de factura positivista había sido puesta de moda por la intelectualidad oligárquica latinoamericana: Juan Álvarez, César Zumeta, Alcides Arguedas, Salvador Mendieta, Manoel Bonfim, entre otros (Funes y Ansaldi, 1994). González Prada, quien había transitado y residido en Burdeos, París y Madrid, tuvo conocimiento de primera mano del impacto urbano de las ciencias biomédicas, así como de las ideologías higienistas y sus legitimadas prácticas sanitarias y arquitectónicas ${ }^{7}$. Lo que no aceptó fueron los anclajes racistas y clasistas del higienismo, reelaborando sus referentes para su propio ejercicio de la crítica de la ciudad darwinista y la oligarquía criolla.

Es comprensible que Don Manuel signase a Lima con una metáfora concordante con el discurso medicalizado y positivista de su tiempo. Un despreciable sintoma de lo mórbido, "el núcleo purulento", simbolizaba a la ciudad de Lima, dentro del enfermizo cuerpo nacional. Don Manuel, apelando a una idealizada estética urbana, puso bajo cuerda a la "perla del Pacífico", a la "Sevilla sudamericana", mostrando su real fealdad arquitectónica, sanitaria y cultural (González P., 1933, p. 163). Apretar el pus con la palabra inflamada o el dedo índice cumplía una función profiláctica, antioligárquica.

El filo crítico de González Prada se acentuó cuando caracterizó a Lima como un dique de contención de la modernidad, casi en el rango de las ciudades europeas de "tercer o cuarto orden". La lógica del higienismo decimonónico alimentó en su obra un inventario de lo negativo urbano: a la ausencia de servicios de limpieza, drenaje, alcantarillado y pavimentación, se sumó la carencia de aireación arquitectónica, o mejor dicho, la afirmación del reino de los miasmas, el moho y las inmundicias. Lima, escribió Don Manuel:

Tiene fisonomia vetusta, aire de cosa exhumada, aspecto de una Pompeya medioeval. Aquí 
se asfixia el hombre organizado para respirar un ambiente moderno, aquí no puede saborear "ese buen aire de París que, según Flaubert, parece contener efluvios amorosos y emanaciones intelectuales". Gracias a los municipios gobiernistas, ineptos el vaho de las alcantarillas mal cerradas, el aroma de basuras aéreas y terrestres, el polvo de calles sin pavimentar o con pavimento irrisorio, y el miasma de charcos en putrefacción [...]. Con la ridícula modernización de sus antiguallas inmodernizables y las nuevas casas de estilo rastá nuestra capital es una vieja verde que se figura estar muy chic y a la moda con su traje de segunda o tercera vida, sus perifollos descoloridos y su relente moho disuelto en naftalina (González P., 1933, p. 162).

González Prada, por oposición a la ciudad oligárquica, miasmática y no moderna, deslizó algunos atributos positivos de la soñada arquitectura y vida parisina. Confesaba que, después de vivir un tiempo en "una ciudad moderna", la depresión se volvió inevitable en el reencuentro con Lima, tanto que, se preguntaba con despiadado humor negro, si los "vivos de nuestras calles y plazas ¿encierran más vida que los muertos del panteón?" (idem.) En otro artículo usó otra variante de la máquina tentacular: el trapiche símbolo de los ingenios azucareros y de la arcadia modernizadora de la oligarquía terrateniente criolla-, para impugnar el orden clasista del sistema de recaudación de impuesto de la ciudad capital, que, en beneficio de los ricos, hacía crujir y moler la carne del agobiado contribuyente (González P., 1938, p. 214).

Nuestro ensayista cuestionaba la verticalizada y clasista profilaxis social, es decir, los modos de control y exclusión de la plebe nacional de indios, negros, y de sus mezclas. Frente a la interesada construcción higienista de la pestilencia del pobre, con la que las burguesias metropolitanas y las oligarquías criollas justificaron sus excesos controlistas ${ }^{8}$, Don Manuel le opuso la imagen de la hediondez moral, política y cultural de las élites y sus agentes represores. Imagina que ellas "...sienten la trepidación del suelo, y no comprenden que es el paso de la revolución en marcha; respiran en atmósfera saturada por hedores de cadáver, y no perciben que ellos y todo el mundo burgués son quienes exhalan el olor a muerto" (González P., 1946, p. 55).

La figura y función represora del policía en la ciudad le parece abominable: "Desde los primeros años, casi desde la cuna misma, el policía amarga y entristece la vida del hombre..." (González P., 1948, p. 101102). ¿Quién concentra mayor fetidez y suciedad que el agente de policía? $\mathrm{Ni}$ siquiera juntos el limpiador de albañales y el deshollinador de chimeneas equiparan en suciedad y pestilencia al policía. Por eso, nuestro autor invita al "indio motoso" a que rechace el oficio más vil y sucio, el de agente policial. 
Cualquier trabajo es mejor, le dice al indio, "...porque despidiendo malos olores, chorreando inmundicias, aparecerás menos hediondo y más limpio que instalado en una esquina, con tu vestido caqui, tu gorra blanca y tu vara de la ley" (González P., 1948, p. 103).

El discurso médico e higienista de González Prada fue revertido contra la propia oligarquía peruana y su ciudad capital, a las que responsabilizó como autoras de las patologías urbanas y nacionales. La reacción del peruano no fue distinta a los críticos de las ciudades darwinistas: el drama obrero y popular no podía pasar desapercibido frente a los destellos de la opulencia, sea bajo el ropaje ideológico del romanticismo social, del socialismo, o del anarquismo (Viñas, 1983, p. 1522). Nuestro escritor tuvo la precaución de no caer en el señuelo de la modernización de los servicios urbanos, como el alumbrado eléctrico o a gas, dada la vulnerabilidad de su abasto, la cual podía revertir la ciudad civilizada en "bosques de bandidos" (González P., 1946, p. 88). La degradada conversión de la ciudad en selva, fue también atribuida a los militares que reprimían y perseguían como "sabuesos y galgos" a los obreros huelguistas, convertidos en "animales de caza" (González P., 1948, p. 40). Para nuestro ensayista latinoamericano, había una clara distinción entre el bárbaro de la ciudad y el civilizado, aunque el primero presumiese de las modas y los bienes que brindaba la modernización a fines del siglo XIX. Así escribió en 1898:
¿Acaso el hombre civilizado se caracteriza por sólo cubrirse de paño y alumbrarse con luz eléctrica? La civilización se mide por el encumbramiento moral, más que por la cultura científica: quien al minimun de egoísmo reúne el máximum de conmiseración y desprendimiento, se llama civilizado; quien todo 1o pospone al interés individual haciendo de su yo el centro del Universo, debe llamarse bárbaro; más que bárbaro, ave de rapiña (González P., 1938, p. 227).

En el imaginario burgués, afirmaba González Prada, se había construido un nuevo y temible enemigo de la ciudad: el anarquista, el bárbaro primitivo, el "enemigo jurado de vida y propiedad ajenas, un energúmeno acometido de fobia universal y destructiva, una especie de felino extraviado en el corazón de las ciudades" (González P., 1948, p. 11). Consideraba que la fiebre anarquista se reprodujo en los medios obreros como "germen de rebelión", aunque consideraba que la acción de las multitudes era intuitiva, distando de ser consciente. En la obra de González Prada hubo una oscilación valorativa de la acción de masas: entre la voluntad utópica y su servilismo burgués. La multitud con la "...blusa del obrero, se manifiesta indisciplinada y rebelde; con el uniforme del recluta, se vuelve sumisa y pretoriana. El soldado fusilador del huelguista, ¿de dónde sale?» (González P., 1948, p. 20).

Nuestro autor, desde su mirador ético anarquista, pensó y juzgó a la 
ideología racista de las oligarquías, así como a sus inventados linajes aristocráticos. Veamos el panorama republicano continental en los propios términos del autor, signados por los atributos más repudiables:

Esa gran división de clases no dejamos de palparla en nuestra América republicana donde las familias acaudaladas van constituyendo una aristocracia más insolente y más odiosa que la nobleza de los Estados monárquicos: a fuer de advenedizos, nuestros falsos aristócratas llevan a tal grado la presunción y el orgullo que sobrepasan al señor de horca y cuchillo. Descendientes (por línea torcida) de aquellos españoles que sufrían de mal del oro, nuestros hidalgos de llave maestra, y ganzúa no tienen más que un sólo deseo: juntar dinero. De ahí que habrán monopolizado el ejercicio de la autoridad, nos hayan dado unas repúblicas de malversaciones y gatuperios, cuando no de oprobios y sangre (González P., 1948, p. 107).

Para el pensador peruano, la fuerza colectiva de la evolución nacional y sus Mesías no podrían salir de la capital peruana: "La desinfección nacional no puede venir del foco purulento: la acción necesaria y salvadora debe iniciarse fuera de Lima para redimir a los demás pueblos de la odiosa tutela ejercida por grupillos de la capital" (González P., 1933, p. 171).

\section{Ciudad, civilización y colonialismo a debate}

En la primera mitad década del 60 del siglo XX, Rodolfo Stavenhagen y Pablo González Casanova sustentaron la teoría del colonialismo interno con ligeras variantes, la cual ponía en evidencia el papel de la ciudad como eje de la dominación y expoliación de su hinterland rural-urbano, así como su dislocamiento frente a la nación. En los hechos, la imagen de la burguesía nacional ocupó su real lugar como burguesía nativa. En el pensamiento anarquista encontramos antecedentes de esta crítica, los cuales merecen ser rescatados, según nos lo recuerdan González Prada y Eliseo Reclus.

Lima le mereció otra crítica a González Prada, acaso inspirada en la lectura de La evolución de las ciudades (1895) de Eliseo Reclus, quien observaba, con preocupación, la función tentacular de las capitales y de algunas grandes ciudades, como "el sintoma de una extraña enfermedad social" (Reclus, 1999: 87), así como la clasista concentración artificial de recursos políticos, militares y económicos en manos de las élites, coexistiendo con la miseria y la contaminación. La figura simbólica del pulpo le permitió a Reclus eslabonar, desde la ciudad, los sentidos de depredación y asfixia del entorno rural y campesino.

En la lectura de González Prada existe una carga más higienista y mecánica en su cuestionamiento del excesivo centralismo que se ejercía desde Lima hacia las provincias. Sin 
lugar a dudas, la proximidad entre el abrazo tentacular del pulpo urbano de Reclus, y la dualidad del artefacto mecánico extractor y recolector de la ciudad del peruano, no supone identidad de criterios, pero si convergencia o equivalencia de imágenes:

La capital es una bomba aspirante que chupa los jugos de toda la Nación, y también una especie de albañal colector o cloaca máxima a donde acuden a reunirse las deyecciones de todas las provincias. Como en Lima se reparte los bocados más suculentos, abundan las tentaciones y caídas; como en Lima se aglomeran también los malos elementos o miasmas deletéreos, no faltan los envenenamientos precoces (González P., 1939, p. 173).

La crítica del paradigma de la modernidad que irradiaban el evolucionismo y el positivismo como ideologias legitimantes de la desigualdad y la injusticia fue realizada y sostenida desde la razón oculta del pobre, es decir, desde la ética del "bárbaro" de la civilización capitalista. Además, la crítica a la modernidad se expresaba en defender un cierto equilibrio entre razón y sentimiento. Y es que el "civilizado" distaba de guiarse solo de razones; su corazón era fuente de signos contradictorios, "oculta(ba) siempre un salvaje». La escalada neocolonial prusiana en Asia y África le llevaron a desarrollar una crítica sostenida del racismo que acompañaba a sus presuntas cruzadas civilizadoras de las manadas de tigres teutónicos con figuras de hombre. Para el autor de Anarquía: "Media más distancia del salvaje prehistórico al hombre moderno que del hombre moderno al individuo de la futura sociedad anárquica" (1948, p. 117).

Don Manuel ejerció una sostenida crítica de la modernidad a través de la revelación de los signos depredadores e irracionales de las prácticas civilizadoras de la ofensiva neocolonial. Tal postura convergió con el movimiento intelectual de ruptura epocal, en el que participaron Martí, Darío, Rodó y Vargas Vila, entre otros. Para todos ellos, las metáforas en clave anticolonialista, más allá de sus divergencias, impugnaron el positivismo spenceriano que reificó y sacralizó la misión civilizadora del capitalismo occidental ${ }^{9}$. La noción de civilización fue cuestionada por nuestro pensador rebelde, rompiendo con el criterio evolucionista unilineal y afirmando la existencia de tipos de civilización marcados por referentes nacionales. En su conjunto, la civilización fue cuestionada como ideal, como principio teleológico, como valor moral:

E1 bárbaro que desea civilizarse $\mathrm{y}$ adquirir como principio una creencia religiosa, quedaría perplejo si oyera al cismático griego hablar contra el protestante, al protestante contra el musulmán, al musulmán contra el católico y al católico contra todos los creyentes y no creyentes. E1 zar que azota y manda a Siberia; el Emperador alemán que orde- 
na la matanza de China sin respetar sexo ni edad, ¿'son tipos de civilización? (González P., 1989, p. 234).

Conocido es el hecho de que en el seno del ala radical de los modernistas creció la idea de que los burgueses civilizados de Estados Unidos o Europa fueron, en realidad, más bárbaros o salvajes que los pueblos de color de este y otros continentes periféricos, tanto por sus extravios antihumanistas, como por expresar la crueldad instintiva, reñida con la razón y el sentimiento justo. Así, González Prada, en fecha temprana, como 1899, confrontó a los socialdarwinistas españoles, quienes consideraban a los habitantes de este continente como involucionados, con aceradas preguntas cargadas de ironía:

¿Cómo se explica que los gorilas San Martín, Bolivar y Sucre derrotaran al hombre español? ¿Cómo se explica que los gorilas Bello, Baralt y Cuervo hayan enseñado y enseñen castellano al hombre español? ¿Cómo se explica, en fin, que hoy mismo veinte o veinticinco mil gorilas de Cuba acaben de tener en jaque a más de doscientos mil hombres españoles? (González P., 1899).

Se trataba de tres interrogantes críticas que se correspondian con lo político y lo intelectual, en donde los "gorilas" latinoamericanos quedaban situados en clave evolucionista arriba del "hombre español». La sustitución del salvaje por el gorila llevaba iróni- camente la confrontación de ideas al mismo terreno del pensamiento darwinista. Lo anterior evidenciaba la dificultad del escritor peruano para sustraerse a las imágenes e ideas del pensamiento evolucionista, aunque haya desplegado, desde sus bordes, una relectura crítica de la civilización y su matriz eurocéntrica.

En la primera y tercera pregunta de la cita, González Prada abordó el asunto político-militar de la independencia sudamericana y cubana, enlazándolos positivamente como cátedra dictada al hombre español. Nos referimos al papel de los líderes (San Martín, Bolivar y Sucre) ${ }^{10}$ $\mathrm{y}$ al de la plebe armada (los veinticinco mil "gorilas" cubanos). En el segundo, reivindicó la apropiación paradigmática del castellano de los filólogos venezolanos Andrés Bello (1781-1865) y Rafael Baralt (1810-1860), así como la del colombiano Rufino Cuervo (18441911); todos ellos dieron cátedra al hombre español. En el texto existe una interpelación adicional alusiva a la conquista y la dominación colonial hispana, como proceso de envilecimiento de los indígenas y negros e indígenas. Afirmó así:

... en la América Española hay millones de indios y miles de negros que no llevan en sus venas una sola gota de sangre castellana; pero verdad también que los negros y los indios han vivido por algunos siglos bajo la exclusiva dominación de España, de modo que intelectual y moralmente deben ser considera- 
dos como sus propios hijos. Los negros o animales de campo, lo mismo que los indios o animales de mina, se hallan en el caso de argüir a sus antiguos amos: "Si somos malos ¿por qué no impidieron ustedes la degeneración?». Cuando los animales domésticos degeneran, cúlpese al dueño, no al animal (González P., 1989).

Sin lugar a dudas, para González Prada, el simbólico "gorila" del nuevo mundo, el salvaje americano, podía civilizar al otro, al europeo, y particularmente al español. En la concepción del escritor peruano subyace una concepción moral de la evolución humana y una visión disidente de la civilización. En el pensamiento de nuestro escritor, los bárbaros distaron de agotarse en las fuerzas coloniales y neocoloniales; también contaron los bárbaros criollos, los guerreros y represores nativos ${ }^{11}$. En general, el envilecimiento de los "blancos" fue remitido por nuestro autor a cierta explicación psicológica. Así afirmó: "El ansia de lucro, la fiebre del oro, hacen del hombre pálido una fiera implacable y sanguinaria" (González P., 1948, p. 59).

Las matanzas de indígenas, perpetradas por los caucheros colonizadores de la región amazónica, orillaron a González Prada a interpelar ese proceso abominable de colonialismo interno, tanto desde la coyuntura del boom cauchero, como en su espejo primigenio, situado en el tiempo largo:

¿Quiénes merecen el título de salvajes: los indios bravos que habitan los bosques o los blancos y mestizos que van a civilizarles? Cuando los españoles vinieron a sembrar la civilización entre los Incas, resultó que los súbditos de Carlos V eran moralmente inferiores a los descendientes de Manco Cápac: hoy está sucediendo que nuestros emisarios y colonos en el Madre de Dios se muestran más salvajes que los Guarayos y los Campas (1941, p. 112).

Se atisba, en esta apreciación de González Prada, una coincidencia con Martí, en especial en la manera de construir ciertas metáforas alusivas al neocolonialismo, en las que destacaron su condición de bestias depredadoras (águilas, tigres, etc.). Pero esta clasificación zoomorfa de los grupos de poder se hizo extensiva a los caudillos, hacendados y burgueses nativos (tiburones).

González Prada no desarrolló el discurso sarmentino sobre la modernidad, por el contrario, lo recusó desde sus ideas sobre la unidad de la especie humana y la moral igualitaria. Optó por configurar una modernidad deseable, que eslabonase implícitamente la política, la técnica y la cultura. De este modo, en su lectura del imperialismo americano resumió su postura al decir:

Admiramos al pueblo yankee por la eminencia de sus hombres desde Washington hasta Edison, por el emancipado espíritu de sus mujeres y por el amplio desarrollo de su instrucción 
pública; pero lo execramos por su implacable ferocidad para con el piel roja, el negro y el huelguista (González P., 1941, p. 150).

Y en lo que respecta al campo más puntual de las innovaciones técnicas y científicas, González Prada asumió una postura convergente con la expuesta por el mexicano Ricardo Flores Magón: subordinada al interés de las clases productoras. Para el pensador sudamericano, la pérdida de la moral por el explotador lo terminaba alienando más que a los trabajadores que explotaba y oprimía. El ser tigre fue la negación de la condición humana, porque antepuso el instinto de rapacidad (afán de lucro), a la razón moral. Por regla general, los dominadores se acercaron al indio para engañarlo, oprimirlo o corromperlo, fueran nacionales o extranjeros. Así afirmó Don Manuel:

...cuando los europeos se hacen rescatadores de lana, mineros o hacendados, se muestran buenos exactores y magníficos torsionarios, rivalizan con los antiguos encomenderos y los actuales hacendados. El animal de pellejo blanco, nazca donde naciere, vive aquejado por el mal del oro: al fin y al cabo cede al instinto de rapacidad (González P., 1975, p. 105).

\section{Cierre de palabras}

Nuestra aproximación al pensamiento libertario acerca de la ciudad real desencantada, signada por la desigualdad y el autoritarismo, marcó un hito en la historia del pensamiento crítico de Europa y de Nuestra América. Gracias a este tipo de pensadores y a veces, actores, la ciudad darwinista fue interpelada y juzgada como no deseable, abriendo la posibilidad de imaginarla y asumirla colectivamente de otra manera. Para ellos, la ciudad moderna, que pretendía tener las llaves del bienestar, la gran cultura y el progreso, fue parcialmente desnudada, mostrando sus excrecencias y lastres, sin llegar a romper con la matriz evolucionista.

Coincidencias, proximidades $\mathrm{y}$ préstamos ideológicos nutrieron a este sector de los intelectuales de filiación anarquista y socialista radical tanto en su crítica a la ciudad o ciudades de su tiempo, como al curso civilizatorio neocolonial. En ese contexto, hemos particularizado, la presentación crítica de las ideas de Manuel González Prada, sin olvidarnos de su lugar de enunciación, Lima. 


\section{NOTAS}

1 "Las ciudades, conectadas entre sí con ferrocarriles y líneas de navegación, son organismos que han vivido siglos. Si cavásemos en sus suelos encontrariamos superpuestas calles, casas, teatros, circos y edificios públicos. Si profundizásemos en su historia, veríamos cómo la civilización de la ciudad, su industria y su genio, han crecido y madurado lentamente por acción de todos sus habitantes antes de llegar a ser lo que son" (Kropotkin, 2005, p. 24).

2 "... se ha demolido poco y se ha edificado mucho en las ciudades pequeñas. Sus arrabales, cuando los tenían, han ido a confundirse con el campo, obteniéndose así amplitud en el centro de ellas, pero las ciudades se conservan con sus calles, plazas y mercados. Esas pequeñas ciudades pueden darnos hoy idea de lo que eran las ciudades en el mundo antiguo" (Morris, 1925, p. 91).

3 "Aquí entramos todos con alegría, llenos de noble serenidad, con la firme resolución de realizar grandes cosas. Aquí todos tendrán pan, tan dificil de obtener fuera, porque hay que conseguirlo mediante inmensas dificultades y vergonzosas humillaciones; todos poseerán la salud que dan el aire puro y el agua abundante de cristalinas fuentes, disfrutarán de una alimentación sencilla, regulada por el trabajo. Es esa ciudad todo un microcosmos funcionará sin esfuerzo, resumen y al mismo tiempo esperanza del género humano, ocupándose en las mil tareas que la vida requiere, tareas siempre atractivas, puesto que serán libremente escogidas. Los artistas adornarán palacios familiares con frescos y esculturas; nos instruiremos mutuamente en los laboratorios, museos y jardines; las doncellas cantarán a coros sublimes melodias; y los niños rodearán en sus alegres corros a los ancianos dichosos; ninguna ley, ninguna imposición perturbará lo más mínimo el gran acuerdo, la augusta conformidad.

"iSalud y alegría a todos los amigos desconocidos que he encontrado en la nueva ciudad! ¡Salud y alegría a todos los que en ella vivan a través de los siglos!». Reclus, E. "La ciudad del buen acuerdo" (1895). Reproducido en: Homobono, 2009, p. 171.

${ }^{4}$ Reclus, E. "La evolución de las ciudades". (1869) Reproducido en: Homobono, 2009, p. 155.

${ }^{5}$ La relación entre Reclus y Kropotkin, además de tener afinidad de ideas, fue amical. Lo refrenda el prólogo del primero a La Conquista del Pan.

${ }^{6} \mathrm{~A}$ un año de la edición francesa, salió traducida al castellano y publicada en América Latina: Grave, Jean (1896) La sociedad futura, traducción de Luis Marco, Buenos Aires: P. Tonini.

${ }^{7}$ En Madrid, durante el último tercio del siglo XIX, el positivismo y darwinismo iban de la mano en las posturas de la intelectualidad burguesa (José de Perojo, Luis Simarro, Manuel Revilla, Pompeyo Gener, Pedro Estasén y José Ustáriz) (Otero, 2000).

8 "Subrayar la fetidez de las clases trabajadoras, y por ende, poner el acento sobre el riesgo de infección que su sola presencia comporta, contribuye a mantener dicho terror justificativo, en el cual la burguesía se complace, y que pone un dique a la expresión de su remordimiento. Así se encuentra inducida una estrategia higienista que simbólicamente asimila desinfección y sumisión" (Corbin, 1982, p. 159).

9 Así, por ejemplo, La Revista Positiva, el prestigiado vocero de los positivistas mexicanos, donde colaboraron el chileno Larraguirre y la peruana Margarita Práxedes Muñoz, publicó, empezando el siglo XX, varios artículos de explícito tenor anticolonialista.

${ }^{10}$ Esta inclusión de San Martín al lado de Bolívar, como veremos más adelante, desaparecerá al ritmo de la construcción de su bolivarolatría.

${ }^{11}$ González Prada, en fecha temprana como 1887, escribió: «En oposición a los políticos que nos cubrieron de vergüenza i se levantan los literatos que prometen lustre i nombra día. Después de los bárbaros que hirieron con la espada vienen los hombres cultos que desean civilizar con la pluma" (1894: 35). 


\section{BIBLIOGRAFÍA}

Bruun, G. (1964). La Europa del siglo XIX 1815-1914. México: Fondo de Cultura Económica.

Capelo, J. (1895) Sociología de Lima. Lima: Imprenta Macías.

Carmagnani, M. (1984). Estado y sociedad en América Latina: 1850-1930. Barcelona: Editorial Crítica.

Corbin, A. (1982). El Perfume y el miasma. El olfato y el imaginario social siglos XVIII-XIX, México, Fondo de Cultura Económica.

Funes, P. y Ansaldi, W. (1994). "Patologias y rechazos. El racismo como factor constitutivo de la legitimidad política del orden oligárquico y la cultura politica latinoamericana». Cuicuilco (México), núm. 2, septiembre-diciembre, pp. 193-229.

Giacchino, M. (1978). Ciencia ficción de la belle époque: Selección de cuentos publicados en revistas populares del siglo XIX. Buenos Aires: Fraterna.

González P., M. (1894). Pájinas Libres. París: Tipografia de Paul Dupont.

- (1899). «Españoles y Yankees». Germinal (Lima), núm. 2, enero, p. 50. (1933). Bajo el Oprobio. París: Tipografia de Luis Bellenand et Fils.

(1938). Figuras y Figurones. París: Tipografia de Luis Bellenand et Fils. (1939). Propaganda y ataque. Buenos Aires: Imán.

(1941). Prosa menuda. Buenos Aires: Imán.

(1946). Horas de lucha. Buenos Aires: Americalee. (1948). Anarquía. Lima: Edit. P.T.C.M.

Copé. (1989). El tonel de Diógenes. En: Obras, tomo I, vol. 2, Lima: Ed. (1975). "Nuestros Indios». En: Podestá, B. Pensamiento Politico de González Prada. Lima: Instituto Nacional de Cultura, pp. 105-106.

Homobono Martínez, J. I. (2009). «Evolución y renovación de las ciudades. Selección de textos de Élisée Reclus». En: Zinak, núm. 31, pp. 117-211.

Kropotkin, P. (2005). La conquista del pan. Buenos Aires: Libros de Anarres.

Morris, W. (1890). News from nowhere: Or an epoch of rest: being some chapters from a Utopian romance. Boston: Roberts Brothers.

Munford, L. (2012). La ciudad en la historia. Sus origenes, transformaciones y perspectivas. La Rioja: Pepitas de Calabaza.

Otero, L. E. (2000). "La ciencia en España. Un balance del siglo XX". Cuadernos de Historia Contemporánea (Madrid), núm. 22, pp. 183-224.

Quiroule, P. (1914). La Ciudad Anarquista americana. Obra de construcción revolucionaria. Buenos Aires: La Protesta. Recuperado de: https://fr.slideshare. net/Exmeridianuslux/quiroule-pierre-la-ciudad-anarquista-americana-utopa-1914, consultado el 19-09-2017.

Reclus, E. (1999). "La evolución de las ciudades». En: Hieraux-Nicolás, D. (Ed.). 
La geografía como metáfora de la libertad. México: Plaza y Valdés editores. Sánchez Albornoz, N. (1977). La población de América Latina. Desde los tiempos precolombinos al año 2000. Madrid: Alianza Editorial.

Viñas, D. (1983). Anarquistas en América Latina. México: Editorial Katún.

Zola, E. (1991). Trabajo. Madrid: Ediciones de la T 